\title{
A Conspectus Of Job Satisfaction: A Cross-Cultural Analysis Of Mexican And American Employees
}

George R. Wagman, Texas A\&M University-Kingsville Joseph R. Villarreal, Texas A\&M University-Kingsville

\begin{abstract}
This study asks employees in the United States and Mexico their perceived feeling of job satisfaction with their employment across service and production industries. The results show unexpected dissimilarities and similarities in the employee responses. Hypotheses based on Hofstede's Individualism (IDV) predicted cultural differences in the two countries would result in a higher perception of workplace satisfaction from employees in the United States than those in Mexico.
\end{abstract}

Keywords: Job Satisfaction, Culture, Mexican, American, Employees

\section{INTRODUCTION}

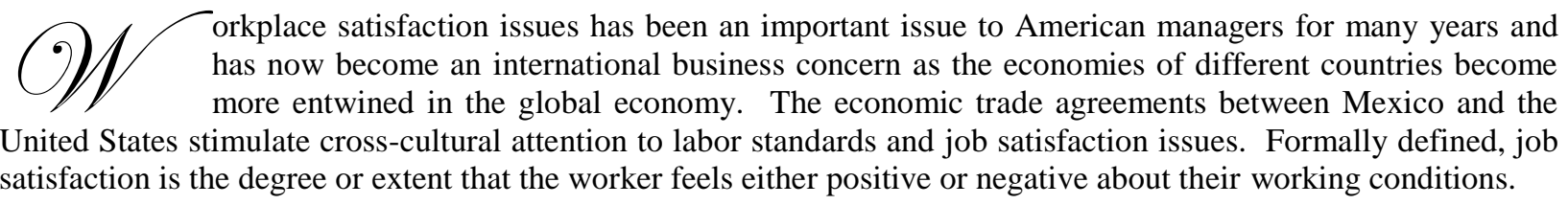

Managers must be astute at recognizing job satisfaction among their employees by observing what they do at work as well as what they say about the job. Dissatisfied workers are more likely than satisfied workers to leave their job (Staw, 1980)

A person's decision to remain with the organization is influenced by job satisfaction as well as influencing absenteeism, failure to attend work, or leave the job entirely. The question of job satisfaction and performance has been a long-time debatable issue: satisfaction causes performance, performance causes satisfaction, and rewards are caused by satisfaction and performance (Green, 1985). After reviewing many published articles, there seems to be very little correlation between satisfaction and performance (Iaffaldano, 1985). Evidence suggest that possibly rewards cause satisfaction not performance (Caudron, 2001). The idea proposed that keeping employees happy just may "be the path of least resistance" (Caudron, 2001). The tendency for managers is to believe that satisfied employees are the productive employees (Fisher, 2003).

\section{MANAGEMENT THEORY}

With the following series of management theories evolving in the United States the view of the employee in the workplace has changed greatly in the past century. At the turn of the last century, with the growth of industrialization in United States, most management views where toward productivity and little or no concern for the employee. In 1911, Frederick Taylor developed the "Scientific Management Theory" with the sole purpose of increasing productivity. Taylor's theory was based on specific measurements and stop watch control of the activities of the worker. The translation of Henry Fayol's "General and Industrial Management" from French to English in 1916 set the view of management as being specific administrative steps. The basic difference between Taylor and 
Fayol's thoughts on management was Taylor reviewed the organization from the bottom and Fayol view it from the top (George, 1968). Max Weber embellished the views of Frederick Taylor with his theory of bureaucracy and the division of management into hierarchy positions insisting upon strong lines of authority and control. With the forming of strong unions in the 1930s and the support of the government, theories began to change to the Human Relations Movement. "Theory X and Theory Y" by McGregor in the 1960s and Elton Mayo's Hawthorn experiment changed the idea that the worker was no longer a commodity but a very integral part of production (George, 1968).

\section{SATISFACTION AT WORK}

Frederick Taylor introduced the idea and referred to the worker as an economic man. He introduced a minimum wage and payment for piecework. The idea that the only motivator or satisfier for the worker was money or a higher wage was held at that time (Taylor, 1911). Henry L. Gantt followed up on Frederick Taylor's idea that money was a motivator and proposed a minimum wage. Although he was ahead of his time, he advocated the importance of the human being at work. He did not speak of job satisfaction; he was a forerunner of the human relations movement (Gantt, 1913). The idea of the importance of the human being at work carried through to the Human Relations Movement and for years most of the research was on the motivation by money. The more money a worker earned the more satisfied the worker would be; therefore, the universal extrinsic reward is compensation (Beatty, 2004).

Business expenses attributed to labor amounts to about two thirds of the total operating expense (Cooper, 2001). Many instruments were designed to measure job satisfaction: focus groups, questionnaires, analytical computer programs (Wmmer, 1992). Two of the more common questionnaires are Minnesota Satisfaction Questionnaire (MSQ) and the Job Descriptive Index (JDI).

The idea proposed by the early writers argued that money was a big motivator and satisfier of the working individual. A fallacy of tying take-home pay to having satisfaction on a job could be argued in compare a single wage rates in Mexico with those of the US worker. The average take-home pay of the US worker would be \$21.97 as compared to a Mexican worker, who earns on an average of $\$ 2.48$ (BLS, 2005). There must be a cultural or value perspective in comparing take-home pay for the US worker as compared to the Mexican worker. There are nonfinancial motivators or satisfiers of having control of your work, having input on the decisions of your work, and having honest and trustworthy supervisors (Pethokoukis, 2006). A study in the late 1990s of 3,351 US employees found that workplace support from the supervisor was the most important factor affecting job satisfaction (Hickins, 1998).

The following have been identified as barriers to advancement in employment: education, ethnicity, disability, age, and gender, had been identified in Mexico and United States. This type of situation in employment practices leads to the denial of access to employment; lower pay, arbitrary termination, and lack of opportunities for advancement, all are factors in job dissatisfaction. The age of the workers also have an influence on the satisfaction of a job. The average working age in Mexico (stating at age 15-24 for males and 25-34 for females)is lower than in the United States(25-34 for males and 35-44 for females) (Wagman, 2004).. NAFTA, (US, Canada, and Mexico) trade group has been having debates on controlling Mexico's Child Labor laws (Bachman, 1997). Midlife crisis or burnout is the state of exhaustion brought on by responsibilities from work and stressors involved in tedious working conditions. In the United States the midlife crisis that affects job satisfaction was assumed to be around the age of 50 and has been reported as occurring earlier at the age of 44 years (ABC, 2008).

Most studies of workplace dissatisfaction focus on disparities in numerical representation of demographics. These provide valuable measures of existing conditions. This study, however, asks employees in the United States and in Mexico if they perceive workplace work satisfaction and to what level. Hofstede's theories of cultural dimensions support an expectation of greater awareness of workplace satisfaction by employees in the United States than in Mexico. 


\section{CULTURAL DIFFERENCES}

Hofstede's theories of cultural differences guide this examination. Specifically, Hofstede's ratings of the Individualism (IDV) for each country support predictions of differences in employee perceptions of their job satisfaction and the opportunities phenomena. As defined on Hofstede's current website (n.d.), Individualism (IDV) focuses on the degree of collectivism or the degree that people are interrelated in their culture or group and on the opposite side the individualist has concern for themselves (Hofstede, 2004). In accordance with Hofstede's IDV's, Mexican employees (30\% IDV) would not have as high expectations for equal opportunities as United States employees (91\% IDV). This difference leads to the following hypothesis.

\section{Hypothesis \# 1}

Employees in the United States service companies will report a higher perception of job satisfaction than employees in Mexican service companies.

\section{Hypothesis \# 2}

Employees in the United States production industries will report a higher perception of job satisfaction than Mexican employees in production industries.

To answer these questions, employees in the United States and in Mexico, employed in a variety of sizes and types of production and service industries, were surveyed about perceptions of job satisfaction.

\section{METHODOLOGY}

In the United States, 273 surveys were collected; 181 were collected in South Texas and 92 in Kansas. There were 181 surveys collected in Mexico. The total number of respondents was 454 . The gender distribution between the two groups was balanced with 139 male and 134 female U.S. respondents and 90 male and 91 female Mexican respondents.

A survey with yes or no response options was developed and translated into Spanish to solicit employee perceptions of several workplace issues. Permission was gained from management prior to conducting the onsite surveys; participation was voluntary and a cover letter assured anonymity and provided for informed consent of the respondents. The surveys were conducted by five graduate students under the direction of Dr. George R. Wagman, Professor of Management, in the College of Business Administration of Texas A\&M University-Kingsville. The survey was conducted in four separate regions: the states of Tamaulipas and Nuevo Leon in Mexico from the cities of Matamoros and Monterrey and in the United States, Kansas and Texas.

Respondents were asked for demographic information and several yes or no response survey questions. One question sought employee perceptions of satisfaction in the workplace through the use of a Likert scale, which ask levels of satisfaction at 5 levels: (very good, good, fair, poor, and very poor). Other questions gave a second variable that of being a service or production industry.

\section{RESULTS}

A two-way contingency table analysis was conducted on both US and Mexico employee data to evaluate whether a statistically significant relationship exists between job satisfaction and business classification. The two variables were job satisfaction with five category levels (very good, good, fair, poor, and very poor) and business classification with two category levels (service and production) as seen below. 


\section{Country=United States}

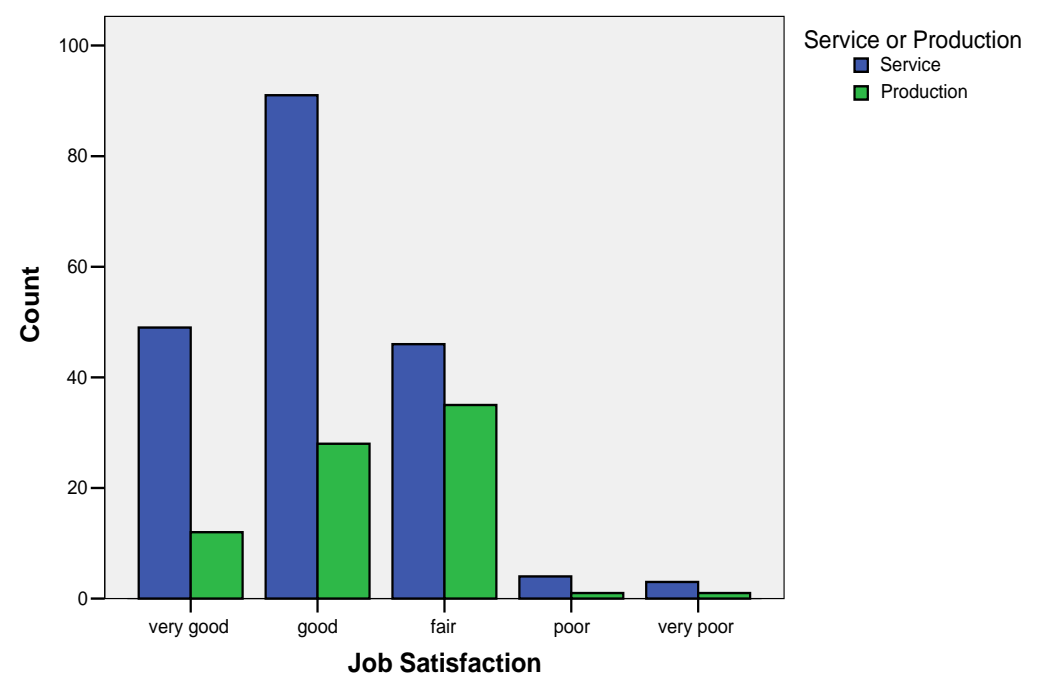

Figure 1: Job Satisfaction and Service or Production for U.S. Employees

For US employees, job satisfaction and service or production were found to be significantly related, Pearson $\chi^{2}(4, N=270)=12.57, p=.014$, Cramér's $V=.216$. As indicated in Figure 1, the proportion of service and production employees who reported "very good" job satisfaction were .25 and .16 respectively. Those who reported "good" satisfaction made up .47 and .36, and employees reporting "fair" were .24 and .46 for service and production respectively. For the US, it appears that service employees reported higher levels of job satisfaction than did production employees.

The following figure shows the statistically significant relationship with Mexican employees in relation to job satisfaction and business classification as seen by the figure below.

\section{Country=Mexico}

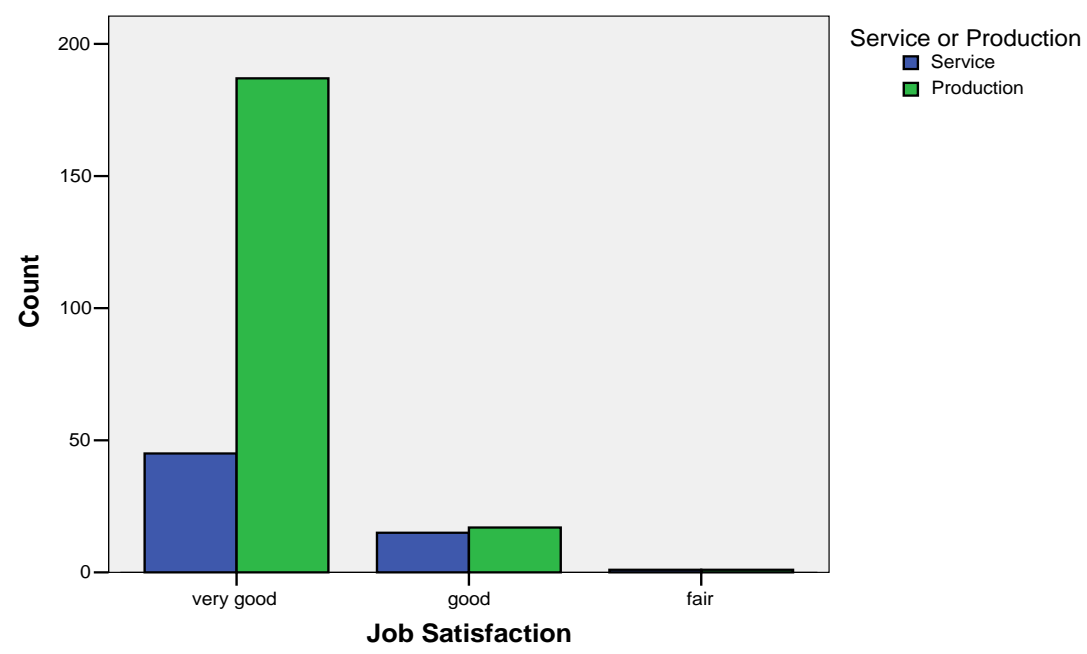

Figure 2: Job Satisfaction and Service or Production for Mexican Employees 
For Mexico employees, job satisfaction and service or production were also found to be significantly related, Pearson $\chi^{2}(2, N=266)=12.85, p=.002$, Cramér's $V=.220$. Figure 2 indicates that the proportion of service and production employees who reported "very good" job satisfaction were .74 and .91 respectively. Those who reported "good" satisfaction made up .25 and .08 for service and production employees. Unlike the US, in Mexico it appears that production employees have higher levels of job satisfaction than do employees from service businesses.

\section{DISCUSSION}

\section{Hypothesis \# 1}

Employees in the United States service companies will report a higher perception of job satisfaction than employees in Mexican service companies.

The first hypothesis was not supported by the data. In the categories of service the employees in the United States only accounted for $0.25 \%$ as compared to employees in Mexico, who made $0.74 \%$ of their respective groups to be "very satisfied" with their jobs.

\section{Hypothesis \# 2}

Employees in the United States production industries will report a higher perception of job satisfaction than Mexican employees in production industries.

The second hypothesis was not supported by the data. In the categories of production the employees in the United States only accounted for $0.16 \%$ as compared to employees in Mexico who made $0.91 \%$ of their respective groups to be "very satisfied" with their jobs.

To answer these questions, employees in the United States and in Mexico, employed in a variety of sizes and types of production and service industries were surveyed about perceptions of job satisfaction. The employees in Mexico in both categories (service and production) reported higher or "very satisfied" with their jobs.

\section{LIMITATIONS AND FUTURE RESEARCH DIRECTIONS}

Analysis of additional demographic indicators including age and ethnicity might contribute to understanding the similarities of perceptions. Future examinations might explore differences in types of workplace, i.e. large or small, service or production, and government or private sectors. Job satisfaction and personal perception of promotion opportunities could also influence views of workplace treatment.

\section{CONCLUSIONS}

The issue of family and that of an extended family, work groups, and friends tie the Mexican culture together. The individualistic feeling held by Americans sets them apart and gives them the perspective that they must look out for themselves. This could be a century old idea set in motion by Horace Greely, when he wrote in the New York Times, "Go west young men and strike out for yourselves."

This study initiated an examination of workplace discrimination from the employee's perspective rather than the standard measurements of representation and salary attainment. These results imply that management must address perceptions of discrimination as well as actual representation and pay disparities.

The cultural differences predicted by Hofstede's cultural dimensions theory were not sustained by the data collected in this study. Employees in both Mexico and the United States indicate that less than half believe there is workplace discrimination based on gender, age, or ethnicity. However, the $43 \%$ of U.S. and Mexican employees who do perceive workplace discrimination is a substantial number and warrants examination. Issues of gender, age, 
and ethnic discrimination in the workplace warrant further examination from the employee perspective. Hofstede's theories of cultural differences guided this examination of employees in both Mexico and the United States. Specifically, Hofstede's ratings of the Individualism (IDV) for each country support predictions of differences in employee perceptions of their job satisfaction and the opportunities phenomena.

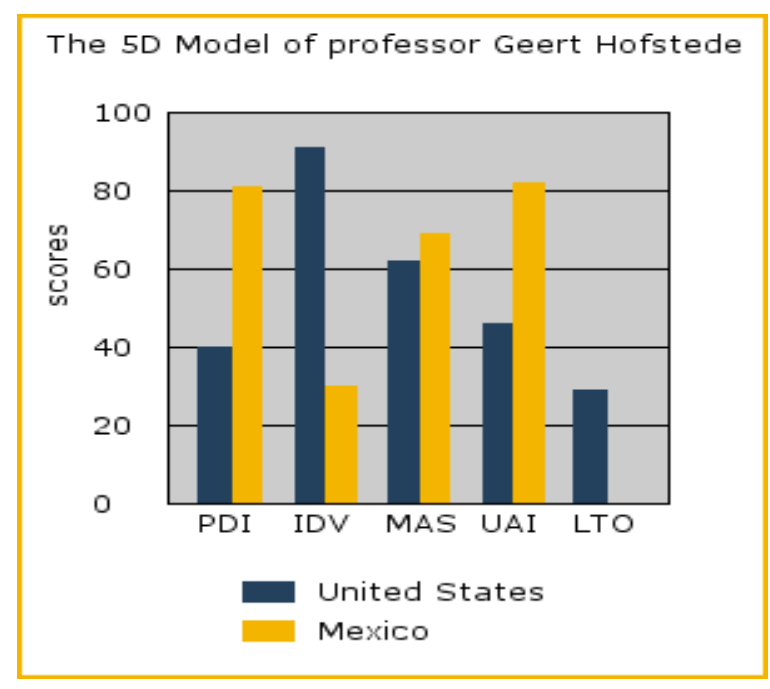

Figure 4: Comparison of U.S. and Mexico on all Cultural Dimensions. (Geert, n.d.).

\section{SUBORDINATE EXPECTATIONS}

Diaz-Saenz and Witherspoon's (2004) study suggests great influence of the Mexican culture on the cultures of work organizations, and the evolution of communities within them.

Latin American subordinates would have the following expectations about their work environment if sense of community would take place:

(a) Sense of community would take place when affective ties among work members are promoted.

(b) Affective ties would continue outside the workplace.

(c) Sense of community would occur if legitimate groups are formed within the organization.

(d) Family and religion would be considered by organization's Human Resources practices.

(e) Organizational members need perceive the roles of family members portrayed within peers or superiors in order to encourage member integration and participation (Diaz-Saenz \& Witherspoon, 2004).

Issues of gender and age in the workplace warrant further examination from the employee perspective.

\section{AUTHOR INFORMATION}

George R. Wagman, PhD, Professor of Management In the Management \& Marketing Department, at Texas A\&M Kingsville..

Joseph R. Villarreal, ABD, Lecturer In the Management \& Marketing Department, Texas A\&M Kingsville. 


\section{REFERENCES}

1. ABC, abc.com/report on the midlife crisis, January 23, 2008, Evening edition.

2. Bachman S. L. USNews.com: Young Workers in Mexico's Economy, 9/1/97.

3. Beatty, J. E. (2004), Grades as Money and the Role of the Market Metaphor in Management Education. Academy of management learning and education, 3: 187-196.

4. $\quad$ BLS Report, prepared by U.S. Department of Labor-Bureau of Labor Statistics, Office of Productivity and Technology, September 30, 2005. 2003 Wage rate in US: \$21.97 \& Mexico: \$2.48.

5. Caudron, S. Job Satisfaction May Not Be Everything, Workforce, retrieved February 15, 2001 from website www.workforce.com.

6. Caudron, S. The Myth of Job Happiness, Workforce, retrieved September 6, 2001 from website www.workforce.com.

7. Cooper, J. C. \& Madigan, K. (2001). The Second Half Should be Healthier. Business Week, (9) 26

8. Diaz-Saenz, H. R., \& Witherspoon, P. D. (2004). Possessing a Sense of community: A study of employee perceptions in selected organizations in Mexico. In G. Cheney \& G. Barnett (Eds.), International and Multicultural Organizational Communication 145-169. Cresskill. NJ: Hampton Press.

9. Fisher, C. D. (2003). Why Delay People from believing that satisfaction and performance are correlated? Possible source of a communication theory. Journal of Organizational Behavior, p. 753.

10. Gantt H. L. (1913). Work, Wages, and Profits. New York Engineering Magazine Company $2^{\text {nd }}$ Ed.

11. George, C. (1968), The History of Management Thought retrieved from http://en.wikipedia.org/wiki/Henry Fayol

12. Green, C. N. (1972), The Satisfaction Performance Controversy, Horizons 15: 31.

13. Hickins, M. (1998), Give A Little, Get a Lot, Management Review, p. 6; see also Susan J. Lambert, Added Benefits: The Link between Work-Life Benefits and Organizational Citizenship Behavior, Academy of Management Journal, October 2000, pp. 801-15; Peggy Simonsen, Do Your Managers Have the Right Stuff? Workforce 78, no. 2 (August 1999), pp. 47-52.

14. Hofstede, G. (n.d.). Cultural dimensions. Retrieved August 28, 2004 from http://www.geert-hofstede.com/.

15. Iaffgaldano, M. T. \& Muchinsky, P. M. (1985), Job Satisfaction and Job Performance: A Meta Analysis. Psychological Bulletin 97(9): 251-273.

16. Job Description Index (JDI) is available from Dr. Patricia C. Smith, Department of Psychology, Bowling Green State University: the Minnesota Satisfaction Questionnaire is available from the Industrial Relations Center and Vocational Psychology Research Center University of Minnesota.

17. Pethokoukis, J. USNews.com: Small Biz Watch: Same pay, Higher Satisfaction. Posted 1/28/06.

18. Staw, B. M. (1980), The Consequences of Turnover. Journal of Occupational Behavior 1:253-273)

19. Taylor, F. W. (1911), Shop Management. New York: Harper and Brothers. 22.

20. Wagman, G. (2004). Unpublished research, Comparing United States Workers with Mexican Workers, Texas A\&M University-Kingsville.

21. Wmmer, W. E. \& Carsten, J. M. (1992), Alternative Ways to Gather Opinions. HR Magazine 37(4):71-78. 
NOTES 